\title{
Selection of borage (Borago officinalis) as a seed crop for pharmaceutical uses
}

\author{
N. W. Galwey and \\ A. J. Shirlin
}

Department of Genetics, University of Cambridge, Downing Street, Cambridge CB2 3EH, U.K.

Gamma-linolenic acid (GLA) has been reported to be beneficial in the treatment of a wide range of disorders. It is extracted from the seed of the evening primrose, but the seed of borage is an alternative source of supply with agronomic advantages. Lines of borage of diverse origin were assembled, and selections for increased seed production, oil content and GLA content, and for reduced erucic acid content, were made. All these characteristics except for oil content were clearly heritable, but GLA content was negatively correlated with oil content and positively correlated with erucic acid content. Blue-flowered northern European genotypes had a higher GLA content than white-flowered cultivated genotypes from Spain.

\section{INTRODUCTION}

Gamma-linolenic acid (GLA), taken orally, has been reported to be beneficial in the treatment of mild hypertension, elevated cholesterol levels, premenstrual syndrome, atopic eczema and other disorders (Horrobin, 1984). These effects are probably related to the role of dietary essential fatty acids in determining the properties of membranes (Horrobin and Manku, 1983) and as precursors of prostaglandins, leukotrienes and related substances (Horrobin, 1983). Steroids and non-steroid anti-inflammatory drugs act by modulating the conversion of essential fatty acids to these substances, and their efficacy is therefore likely to be influenced by the availability of the substrates. GLA for pharmaceutical uses is mainly obtained from the seed of the evening primrose, Oenothera spp., in which it is a major component of the oil, but the seed of borage, Borago officinalis, is an alternative source. Until 1989 virtually all evening primrose production in England was of Oenothera biennis, which suffers from the disadvantage of a biennial life cycle, but in continental Europe Oenothera lamarkiana is cultivated as an annual, and this species has recently begun to be cultivated in England also. Borage too has the advantage of an annual life cycle, and it has the additional advantage of larger seeds, making harvest and oil extraction easier. However, borage oil has the disadvantage of containing 1-2 per cent of erucic acid. This compound, although it is an essential fatty acid, is believed to be harmful in large doses, and breeders of oilseed rape have selected for low erucic acid content.

Borage has not been subjected to selection for cultivation as a seed crop, and research was therefore carried out with the aim of developing lines that would be superior to those currently available as a source of GLA. The characteristics to be sought included increased seed production, seed retention, oil content and proportion of GLA in the oil, and a lower proportion of erucic acid.

The literature concerning borage is sparse, but a few papers describe the secondary metabolism of the plant, its ecology and its breeding system. Borage plants were reported to contain rosmarinic acid (Reschke, 1983), unsaturated pyrrolizidines (Larson, Roby and Stermitz, 1984) and dhurrin, a cyanogenic compound (Van Valen, 1979). White light was reported to inhibit the germination of borage seeds and the early development of the seedlings (Theimer and Schuster, 1978). Most interestingly, self-incompatibility in borage was reported to be incomplete and polygenically controlled, and to increase with increasing homozygosity, so that inbred plants had a stronger tendency to outbreed (Crowe, 1971). 


\section{MATERIALS AND METHODS}

\section{Evaluation of germplasm and selection of breeding lines}

The handling of the borage lines and accessions used in this research is described in fig. 1. The first stocks obtained were English, Dutch and Hungarian material supplied by BioCrops Ltd at the beginning of the 1986 growing season, and these were grown in isolated replicated plots. No phenotypic differences between the stocks were noted. Individual plants were harvested at random from these plots. About 70 samples of seed were subsequently received from botanic gardens as far afield as the Argentine and the Ukraine, but about half of these consisted of seed that had been destroyed, presumably by rodents or insects. Additional seed samples were collected in Spain, from 30 sources including roadside populations, cultivated plants in smallholdings and seed companies. A clear distinction was found between the type of borage cultivated in Aragon and the Basque provinces for consumption of the petioles, which is white-flowered and has reduced hairiness and elongated petioles, and the spontaneous blueflowered populations.

In 1986, an English commercial stock of borage was sown in $15 \mathrm{~m} \times 8 \mathrm{~m}$ plots on $21 \mathrm{March}, 4$ April and 18 April. The latter is the commercially recommended sowing date, but the spring was warm and little, if any, natural selection for cold tolerance occurred. About 400 plants were selected, some at random and some for early or late flowering, tall or short stature, or compact or lax cymes. In general, little phenotypic diversity was evident among the plants. Borage plants normally shed their seed as soon as it is mature, and no plants that showed marked retention of mature seed were found.

During 1987 the stocks of borage that had been assembled were evaluated in the field. About 500 accessions and lines were grown in two replications in single-row plots. There was a substantial amount of variation among the accessions from botanic gardens and from Spain. The characteristics that varied included the number of fruits produced per raceme and the number of racemes per plant, the degree of variation in the time of maturity between fruits on the same raceme, the degree of branching of the plant and the date of maturity. There was also some variation in the extent to which the mature seeds were retained. Generally speaking the Spanish cultivated types produced more seed than the spontaneous types, and appeared to retain their seed slightly more. There was also variation in characteristics that are not of direct economic importance but that are useful as indicators of genetic diversity, such as the presence and intensity of blue pigment in the flowers and the colour and hairiness of the foliage. Single-plant selections were made in the most promising accessions. The progeny of single plants selected in 1986 were much less variable, but here too selections were made. Plants were selected in 115 of the accessions and

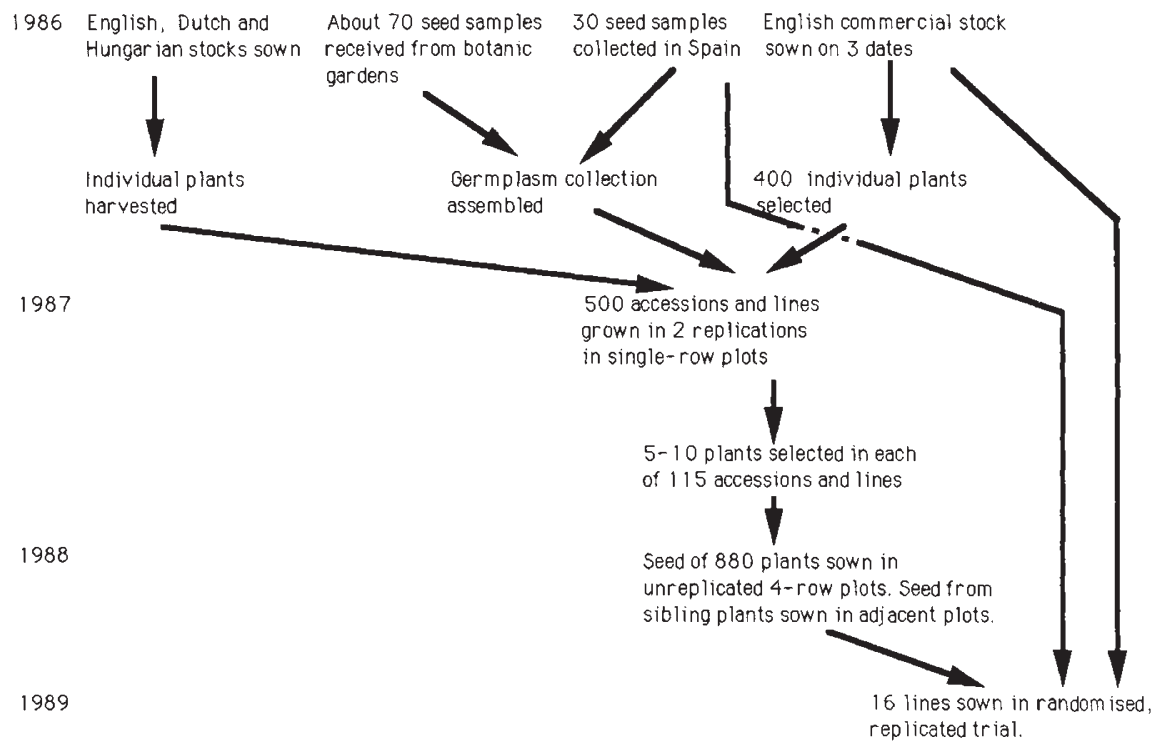

Figure 1 The handling of the borage lines and accessions. 
lines grown. Between five and ten plants were harvested indivudally from each selected line.

In 1988 the seed from 880 of the plants selected in 1987 was sown, some in well-isolated plots, but most in a single trial. The trial was not randomised but was systematically organised with seed from sibling plants sown in adjacent plots, in an attempt to minimise the effect of outcrossing. Each plot consisted of four $1-\mathrm{m}$ rows and the plots were separated by a row of oats, which was intended to reduce cross-pollination between plots. It also served to separate the borage plants physically and make evaluation easier. Establishment was good, and when the plants started to flower in July, differences between the lines were clearly apparent, though due to the design of the trial, statistical analysis could not be used to confirm that these were due to genetic differences. Ninety- three plots were noted for strong expression of diverse characteristics similar to those noted in 1987. Plants from nearly 200 plots, including these, were bagged and harvested. About ten plants per plot were taken.

Following the 1988 harvest, oil analyses were conducted on 31 lines of which sufficient seed was available. In most cases the newly harvested seed was sent, but in some, seed of the original stock was available.

\section{Replicated trial}

In 1989 a replicated trial was conducted of diverse lines of which sufficient seed was available, in order to determine the degree of genetic variation among the lines that had been produced during the project. The 16 lines used are described in table 1 .

Table 1 Lines included in the replicated trial in 1989

\begin{tabular}{|c|c|c|c|}
\hline \multirow[b]{2}{*}{ Line } & \multicolumn{3}{|l|}{ Comments } \\
\hline & $\begin{array}{l}\text { In germplasm } \\
\text { catalogue }\end{array}$ & In 1987 & In 1988 \\
\hline \multicolumn{4}{|l|}{ Blue flowered } \\
\hline $474-4$ & - & Dense cymes & Tall, many fruits \\
\hline $483-3$ & - & Twisted cymes & Very spiny \\
\hline $486-3$ & - & Dense cymes & Dense canopy of cymes \\
\hline $1067-3$ & - & Sparse flowers & Sparse flowers, lodged \\
\hline $1157-4$ & - & Long cymes & Many cymes \\
\hline $78 \mathrm{~B}$ & $\begin{array}{l}\text { Zaragoza } \\
\text { germplasm } \\
\text { accession No. } \\
\text { B6 HZ } 153\end{array}$ & Seed retention & Very tall \\
\hline $82 B$ & $\begin{array}{l}\text { Dipartimento, } \\
\text { Pisa. Wild }\end{array}$ & Seed retention & - \\
\hline 30B. 1986 seed & $\begin{array}{l}\text { Zaragoza } \\
\text { germplasm } \\
\text { accession No. } \\
\text { FD85 }\end{array}$ & - & - \\
\hline $\begin{array}{l}\text { Isolation plot } 1988 \\
\text { (IP88)-Tall }\end{array}$ & - & - & 一 \\
\hline $\begin{array}{l}\text { Isolation plot } 1988 \\
\text { (IP88)-Short }\end{array}$ & - & - & - \\
\hline $\begin{array}{l}\text { Isolation plot } 1988 \\
\text { (IP88)-Dense }\end{array}$ & - & - & - \\
\hline $\begin{array}{l}\text { English bulk. } \\
1986 \text { seed }\end{array}$ & - & - & - \\
\hline \multicolumn{4}{|l|}{ White flowered } \\
\hline $498-2$ & - & White flowers & Many fruits \\
\hline $498-4$ & - & White flowers & Short, many fruits \\
\hline 26B. 1986 seed & $\begin{array}{l}\text { Semillas } \\
\text { Battle } \\
\text { Cert. No. } \\
221269\end{array}$ & - & - \\
\hline 85B. 1986 seed & $\begin{array}{l}\text { Semillas } \\
\text { Veron } \\
\text { Cert. No. } \\
221.433\end{array}$ & - & - \\
\hline
\end{tabular}


They include some selected for valuable characteristics such as free fruiting, and others selected for the absence of such characteristics. The original English stock and white-flowered germplasm accessions from Spain were also included. In these cases, the original seed collected in 1986 was used, so as to avoid the contamination by outpollination that had occurred during the project.

The trial was laid out in a randomised block design with three replications. Each plot consisted of four $2-\mathrm{m}$ rows of borage, with $0.5 \mathrm{~m}$ between rows. The plots were separated by two rows of oats. The trial was sown on 4 May. There was some moisture in the seedbed but a very dry period followed. On 12 June irrigation was commenced, but establishment was poor and erratic. During the growing season, establishment, freeness of flowering and freeness of fruiting were assessed on a 0 to 5 scale. Plant height was measured on 18 July, when the plants from the first flush of germination were flowering, and again on 29 August, when the plants had shed most of their seed.

\section{RESULTS AND DISCUSSION}

\section{Oil content and composition}

The correlations between oil content and composition in the 31 lines analysed are presented in table 2. GLA content and erucic acid content are both negatively correlated with oil content, though in the case of erucic acid content this correlation is not quite significant, and are strongly positively correlated with each other. These correlations are unfavourable, since if they have a genetic basis, lines with a high GLA content in the oil will tend also to have a high content of the undesirable erucic acid, and a low overall oil content.

Since the values of oil content and composition are not replicated it is not possible to assess the heritability of the differences between lines directly, but an analysis was performed that gives some indication of this. The lines were divided into four groups according to their geographical origin, namely the English land race material,
Table 2 Correlations between oil content and composition

\begin{tabular}{llll} 
& & Oil content & GLA content \\
\cline { 2 - 3 } GLA content & $r$ & -0.507 & \\
& $P$ & $<0.01$ & \\
Erucic acid content & $r$ & -0.341 & $0 \cdot 737$ \\
& $P$ & ns & $<0 \cdot 001$ \\
\hline
\end{tabular}

northern blue-flowered germplasm accessions, southern blue-flowered germplasm accessions and white-flowered germplasm accessions (all of which originated in Spain). The three seed samples from plants grown elsewhere were excluded. The results of this analysis are presented in tables 3 and 4 . This analysis indicates that oil content has a very low heritability, but shows a clear difference between the GLA content of the white-flowered lines and lines of the other three origins. Since the seed from the white-flowered lines was produced in the same field as the rest, this must reflect genetic and not environmental differences. The lines had been growing in the field for two generations, during which outcrossing will have blurred differences between them, and the significant difference therefore indicates that GLA content is at least moderately heritable. The GLA content of the white-flowered lines is lower than that of the other groups, and therefore they do not themselves offer an improvement on the blue-flowered stocks currently cultivated. However, this analysis indicates that differences in GLA content of about $2 \cdot 5$ percentage points are heritable, and hence suggests that the lines with contents a similar amount above the average--that is, about 26 per cent-will consistently produce progeny with a high GLA content.

Lines of different origin also differ highly significantly in their erucic acid content. The whiteflowered lines have a lower content than the other three groups, as would be expected on the basis of their low GLA content, and the northern blueflowered lines have a nearly significantly higher erucic acid content than the southern $(t=2 \cdot 04$, $P=0.052$, the English lines being intermediate.

Table 3 Analyses of variance of oil content and composition by geographical origin

\begin{tabular}{|c|c|c|c|c|c|c|c|c|c|c|}
\hline \multirow[b]{2}{*}{ Source of variation } & \multirow[b]{2}{*}{$\mathrm{df}$} & \multicolumn{3}{|c|}{ Oil content } & \multicolumn{3}{|c|}{ GLA content } & \multicolumn{3}{|c|}{ Erucic acid content } \\
\hline & & MS & $F$ & $P$ & MS & $F$ & $P$ & MS & $F$ & $P$ \\
\hline
\end{tabular}

MS, mean square. 
Table 4 Means of oil content and composition in groups of different geographical origins

\begin{tabular}{|c|c|c|c|c|}
\hline Origin & $\begin{array}{l}\text { Number of } \\
\text { lines }\end{array}$ & Oil content $\%$ & GLA content $\%$ & $\begin{array}{l}\text { Erucic acid } \\
\text { content } \%\end{array}$ \\
\hline English & 13 & $32 \cdot 2$ & $23 \cdot 8$ & $2 \cdot 75$ \\
\hline Northern blue & 3 & $32 \cdot 1$ & $23 \cdot 9$ & $2 \cdot 80$ \\
\hline Southern blue & 9 & $30 \cdot 5$ & $23 \cdot 7$ & $2 \cdot 60$ \\
\hline White & 3 & $33 \cdot 7$ & $21 \cdot 3$ & 1.93 \\
\hline Grand mean & 28 & $31 \cdot 8$ & $23 \cdot 5$ & $2 \cdot 62$ \\
\hline \multicolumn{5}{|l|}{$S E_{\text {Diff }}$} \\
\hline $\min -\min ^{1}$ & & $2 \cdot 12$ & $0 \cdot 71$ & $0 \cdot 125$ \\
\hline $\max -\min ^{2}$ & & 1.66 & 0.56 & 0.098 \\
\hline
\end{tabular}

${ }^{1}$ For comparison of means based on minimum number of lines.

${ }^{2}$ For comparison of mean based on minimum number of lines with mean based on maximum number of lines.

SE, standard error.

The GLA contents of the blue-flowered groups are ranked in the same order, though the differences in this case are not close to significance. The content of erucic acid is thus fairly highly heritable, and if an erucic acid content of 3 per cent in the oil is acceptable, it may be more effective to select for a high level of erucic acid, raising the GLA content by a correlated response, than to select for GLA content directly.

\section{Replicated trial in 1989}

Analyses of variance to detect differences in establishment, plant height and the freeness of flowering and fruiting between the blue-flowered and whiteflowered groups of lines, and between the lines within each group, are presented in table 5, and the mean values of each characteristic are presented in tables 6 and 7. Establishment was sig-

Table 5 Analyses of variance of characteristics assessed in the replicated trial

\begin{tabular}{|c|c|c|c|c|c|c|}
\hline \multirow[b]{2}{*}{ Source of variation } & \multicolumn{3}{|c|}{ Establishment } & \multicolumn{3}{|c|}{ Height on 18.7.1989 } \\
\hline & df & $F$ & $P$ & $\mathrm{df}$ & $F$ & $P$ \\
\hline Blocks & 2 & $5 \cdot 38$ & 0.01 & 2 & 3.79 & 0.04 \\
\hline Blue vs. white & 1 & $24 \cdot 18$ & $<0.001$ & 1 & $18 \cdot 05$ & $<0.001$ \\
\hline Among blue lines & 11 & $0 \cdot 81$ & 0.63 & 11 & $1 \cdot 04$ & 0.45 \\
\hline Among white lines & 3 & $1 \cdot 35$ & $0 \cdot 28$ & 3 & $2 \cdot 48$ & 0.09 \\
\hline \multirow[t]{2}{*}{ Residual } & 29 & & & $21^{1}$ & & \\
\hline & \multicolumn{3}{|c|}{ Freeness of flowering } & \multicolumn{3}{|c|}{ Height on 29.8 .1989} \\
\hline Source of variation & $\mathrm{df}$ & $F$ & $P$ & $\mathrm{df}$ & $F$ & $P$ \\
\hline Blocks & 2 & $1 \cdot 04$ & $0 \cdot 37$ & 2 & $2 \cdot 14$ & $0 \cdot 14$ \\
\hline Blue vs. white & 1 & $18 \cdot 32$ & $<0.001$ & 1 & $16 \cdot 82$ & $<0.001$ \\
\hline Among blue lines & 11 & $2 \cdot 16$ & 0.06 & 11 & 0.93 & 0.53 \\
\hline Among white lines & 3 & $1 \cdot 88$ & $0 \cdot 16$ & 3 & $1 \cdot 58$ & $0 \cdot 21$ \\
\hline \multirow[t]{2}{*}{ Residual } & $21^{1}$ & & & 29 & & \\
\hline & \multicolumn{3}{|c|}{ Freeness of fruiting } & \multicolumn{3}{|c|}{ Lodging } \\
\hline Source of variation & $\mathrm{df}$ & $F$ & $P$ & $\mathrm{df}$ & $F$ & $P$ \\
\hline Blocks & 2 & $3 \cdot 73$ & 0.04 & 2 & $6 \cdot 03$ & 0.006 \\
\hline Blue vs. white & 1 & 0.61 & 0.44 & 1 & $14 \cdot 63$ & $<0.001$ \\
\hline Among blue lines & 11 & $3 \cdot 56$ & 0.003 & 11 & $3 \cdot 10$ & 0.007 \\
\hline Among white lines & 3 & $2 \cdot 36$ & 0.09 & 3 & $0 \cdot 23$ & $0 \cdot 87$ \\
\hline Residual & 29 & & & 29 & & \\
\hline
\end{tabular}

${ }^{1}$ Eight degrees of freedom missing due to poor establishment in some plots, which prevented their being scored for this characteristic. 
Table 6 Characteristics that varied among lines within flower-colour groups

\begin{tabular}{|c|c|c|c|c|c|c|c|}
\hline Line & $\mathrm{Oil}^{1}$ & $\mathrm{GLA}^{1}$ & $\begin{array}{l}\text { Erucic acid } \\
\text { content }\end{array}$ & $\begin{array}{l}\text { Height } \\
\text { early }(\mathrm{cm})^{2}\end{array}$ & Flowering $^{3}$ & Fruiting ${ }^{4}$ & Lodging $^{5}$ \\
\hline \multicolumn{8}{|l|}{ Blue-flowered } \\
\hline $474-4$ & $35 \cdot 5$ & $22 \cdot 7$ & $2 \cdot 3$ & 72 & $2 \cdot 0$ & $3 \cdot 3$ & $1 \cdot 0$ \\
\hline $483-3$ & $35 \cdot 2$ & $22 \cdot 7$ & $2 \cdot 6$ & 72 & $0 \cdot 3$ & $2 \cdot 7$ & $2 \cdot 7$ \\
\hline $486-3$ & $33 \cdot 8$ & $23 \cdot 0$ & $2 \cdot 8$ & 65 & $1 \cdot 7$ & $1 \cdot 7$ & $0 \cdot 3$ \\
\hline $1067-3$ & $29 \cdot 0$ & $24 \cdot 2$ & $3 \cdot 0$ & 70 & $1 \cdot 6$ & $3 \cdot 3$ & $3 \cdot 0$ \\
\hline $1157-4$ & $34 \cdot 5$ & $22 \cdot 9$ & $2 \cdot 6$ & 78 & 0.0 & $3 \cdot 7$ & $3 \cdot 0$ \\
\hline $30 \mathrm{~B}$ & - & - & - & 62 & $2 \cdot 5$ & $2 \cdot 3$ & $0 \cdot 3$ \\
\hline $78 \mathrm{~B}$ & $26 \cdot 1$ & $22 \cdot 9$ & $2 \cdot 7$ & 65 & $2 \cdot 3$ & $0 \cdot 0$ & $0 \cdot 0$ \\
\hline $82 \mathrm{~B}$ & $26 \cdot 3$ & $23 \cdot 3$ & $2 \cdot 8$ & 70 & 0.5 & $0 \cdot 3$ & $1 \cdot 0$ \\
\hline IP88-Tall & - & - & - & 77 & $1 \cdot 0$ & $1 \cdot 7$ & $1 \cdot 7$ \\
\hline IP88-Short & - & - & - & 65 & $2 \cdot 3$ & $3 \cdot 0$ & $1 \cdot 0$ \\
\hline IP88-Dense cyme & - & - & - & 72 & $1 \cdot 3$ & $2 \cdot 7$ & $1 \cdot 3$ \\
\hline English bulk & - & - & - & 75 & $1 \cdot 0$ & $3 \cdot 3$ & $2 \cdot 3$ \\
\hline Mean & - & - & - & $70 \cdot 0$ & $1 \cdot 40$ & $2 \cdot 33$ & $1 \cdot 47$ \\
\hline \multicolumn{8}{|l|}{ White-flowered } \\
\hline $498-2$ & $34 \cdot 4$ & $21 \cdot 0$ & $1 \cdot 9$ & 55 & $3 \cdot 5$ & $1 \cdot 7$ & 0.0 \\
\hline $498-4$ & $31 \cdot 8$ & $21 \cdot 9$ & $2 \cdot 0$ & 70 & $2 \cdot 5$ & $1 \cdot 0$ & 0.5 \\
\hline $26 \mathrm{~B}$ & - & - & - & 55 & $2 \cdot 0$ & $3 \cdot 0$ & $0 \cdot 0$ \\
\hline $85 \mathrm{~B}$ & - & - & - & 55 & $3 \cdot 0$ & $2 \cdot 7$ & 0.0 \\
\hline Mean & - & - & - & $57 \cdot 7$ & $2 \cdot 80$ & $2 \cdot 05$ & $0 \cdot 14$ \\
\hline Grand mean & - & - & - & $66 \cdot 9$ & $1 \cdot 75$ & $2 \cdot 26$ & $1 \cdot 14$ \\
\hline \multicolumn{8}{|l|}{ SE of differences } \\
\hline between lines & - & - & - & $7 \cdot 08$ & 0.803 & $0 \cdot 898$ & $0 \cdot 850$ \\
\hline between groups & - & - & - & $2 \cdot 89$ & $0 \cdot 328$ & 0.367 & $0 \cdot 347$ \\
\hline
\end{tabular}

${ }^{1}$ From analysis conducted in 1988.

${ }^{2}$ Measured on 18.7.1989.

${ }^{3} 0=$ free flowering, $5=$ sparse flowering.

${ }^{4} 0=$ free fruiting, $5=$ sparse fruiting.

${ }^{5} 0=$ not lodged, $5=$ badly lodged.

nificantly better in the blue-flowered lines than in the white-flowered. This may have been because old seed was used in two of the four white-flowered lines, or because the white-flowered lines are all cultivated types and are less able to tolerate adverse

Table 7 Characteristics that varied between flower-colour groups

\begin{tabular}{|c|c|c|}
\hline Group of lines & Establishment & $\begin{array}{l}\text { Height } \\
\text { late }(\mathrm{cm})^{1}\end{array}$ \\
\hline Blue-flowered & $2 \cdot 31$ & $66 \cdot 8$ \\
\hline White-flowered & $4 \cdot 18$ & $53 \cdot 8$ \\
\hline Mean & $2 \cdot 77$ & $63 \cdot 6$ \\
\hline $\begin{array}{l}\mathrm{SE} \text { of difference } \\
\text { between groups }\end{array}$ & $0 \cdot 381$ & $3 \cdot 17$ \\
\hline
\end{tabular}

${ }^{1}$ Measured on 29.8.1989. seedbed conditions. At flowering the blue-flowered lines lines were significantly taller than the whiteflowered, and there was also nearly-significant variation within the latter group, line $498-4$ being taller than the others. The blue-flowered lines flowered significantly more freely than the whiteflowered, perhaps partly as a result of the poorer establishment of the latter. There were also nearlysignificant differences in this characteristic within the blue-flowered group, lines 483-3, 1157-4 and 82B producing particularly abundant flowers.

At maturity the blue-flowered lines were still taller than the white-flowered, but the differences within the latter group had disappeared. Despite the difference between the groups in freeness of flowering there was no difference in freeness of fruiting. This was contrary to the observation in 1987 that the Spanish cultivated types produced more seed, and may have occurred because the 


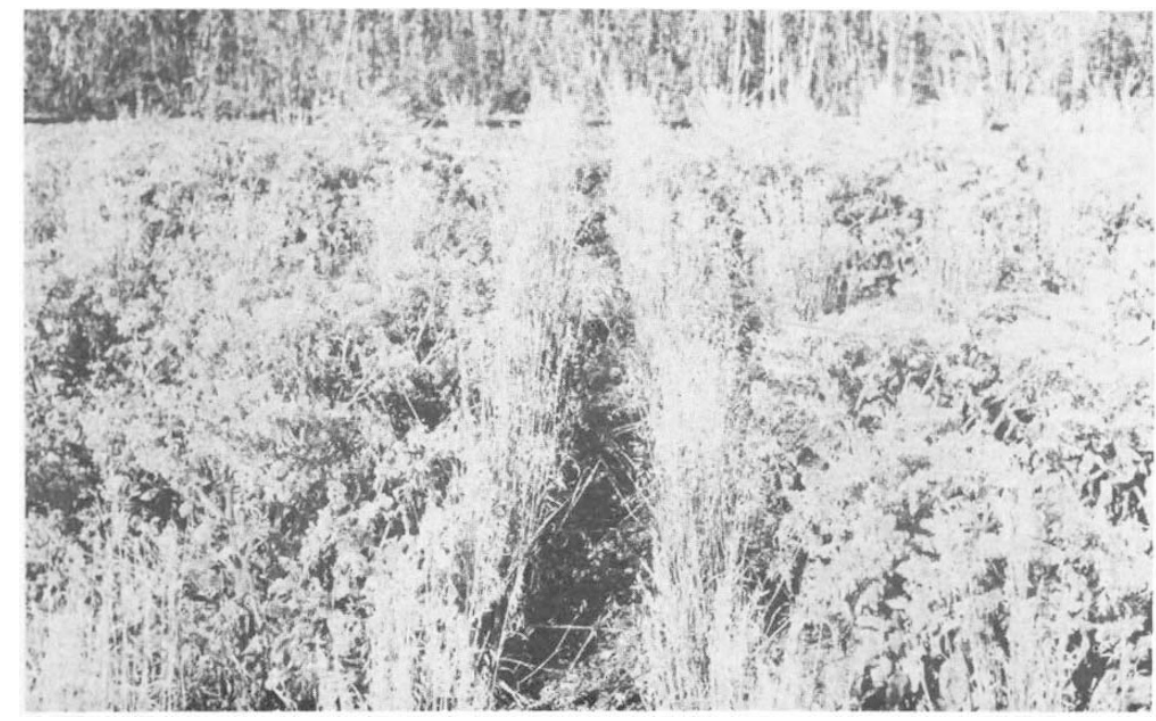

Figure 2 A sparsely fruiting, badly lodged plot of borage on the left, and a contrasting plot on the right.

blue-flowered lines used in the replicated trial had mostly been selected for seed production. However, there were significant differences in freeness of fruiting within the blue-flowered group, and nearly-significant differences within the whiteflowered group. There was no significant association between the freeness of flowering and of fruiting $(r=-0 \cdot 131$, d.f. $=10, \mathrm{~ns})$, and of the three most free-flowering lines only $82 \mathrm{~B}$ was among the most free-fruiting. Other free-fruiting lines were 78B, 486-3 and IP88-Tall in the blue-flowered group, and 498-2 and 498-4 in the white-flowered group. There was significantly more lodging among the blue-flowered lines, probably due to their greater height, and there were also significant differences in this characteristic among the blue flowered lines. The free-fruiting lines generally suffered less from lodging ( $r=0 \cdot 645, \mathrm{df}=10, P<$ 0.05 ), the least lodged lines being 78B, 486-3 and 30B. These differences are illustrated in figs 2 and 3.

Genetic differences may have been partly obscured in this trial by poor establishment, but overall it indicates that lines with heritable differences have been identified. The line selected for sparse flowers and lodging, 1067-3, showed these defects in the trial. The English bulk was also among the least free-flowering. Among the six free-fruiting lines, two, $82 \mathrm{~B}$ and $486-3$, had a GLA content of at least 23 per cent and should be assessed further.

\section{Other approaches to genetic improvement}

In this project, selection was made among openpollinated plants, and though related lines were sown in adjacent plots to encourage inbreeding, open pollination limited the effectiveness of selection. A means of ensuring self-fertilisation would be of great value for the identification and preservation of genetically distinct lines. Attempts were made to control pollination, by excluding bees using cages in the field, and by growing plants in a glasshouse. In the caged plants, seed set was reduced almost to zero, and the plants continued to flower longer. Artifical pollination with a paintbrush was not effective. However, when the temperature in the glasshouse was kept below $18^{\circ} \mathrm{C}$, and the relative humidity was kept high by using a mist line, 56 per cent of artificially pollinated flowers set seed. The action of pollination shook other flowers and released clouds of pollen, resulting in semi-natural setting of seed in about 3 per cent of flowers on average. In the flowers that set seed, the average number of seeds/flower was $2 \cdot 33$ following artificial pollination, and 1.63 following semi-natural pollination. These results were obtained by pollinating mature, blue flowers. When newly opened flowers, the petals of which were still pink, were pollinated, only 7 per cent set seed. These techniques should provide a basis for producing inbred lines and making planned hybrids in future breeding work. 
(a)
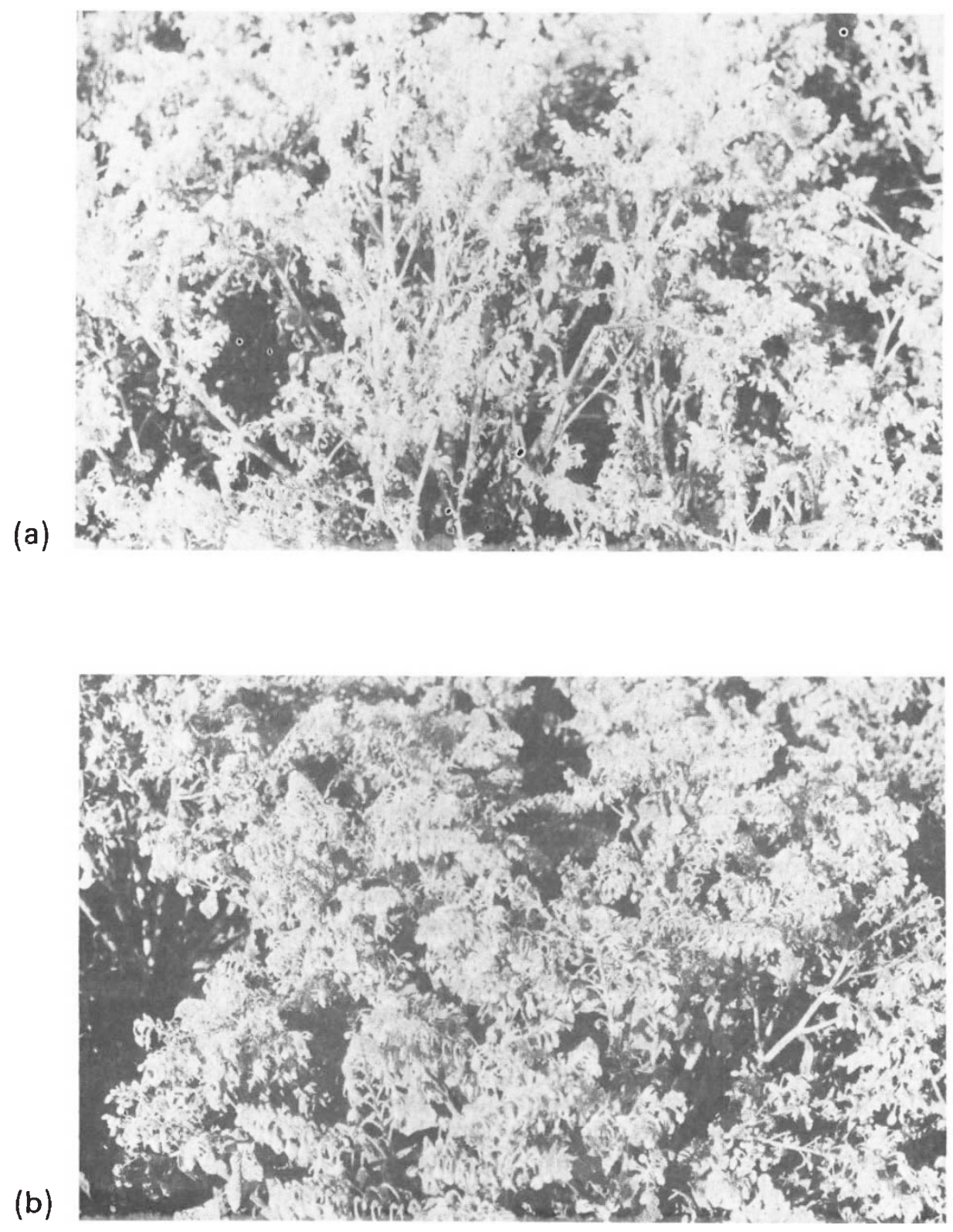

Figure 3 The canopy of a sparsely fruiting (a) and a free-fruiting (b) plot of borage.

An alternative to searching the natural diversity of a species for desired variants is the use of chemical mutagens. This may be particularly valuable when the characteristic sought is one that is not likely to have been favoured by natural selection, as is the case with seed retention. An attempt was made to produce mutant lines by soaking borage seed for a few hours and then immersing the seed in $2 \times 10^{-4} \mathrm{M}$ or $2 \times 10^{-3} \mathrm{M}$ aqueous solution of sodium azide or $0 \cdot 1$ per cent or 1 per cent aqueous solution of ethyl methyl sulphase for one or two hours. These treatments were chosen on the basis of those found to be effective in mutagenesis of other crop seeds, but in borage they produced no evident phytotoxic effects, and no mutant phenotypes in subsequent generations. This is 
probably because borage seeds, which can be very slow to germinate in the field, need a longer period of imbibition than was allowed before they are vulnerable to mutagens.

\section{CONCLUSIONS}

There is considerable evidence that by assembling a broad range of genotypes and conducting four generations of selection in well-grown field plots, we have produced some borage lines that are agronomically superior to the English land race type that was being cultivated at the beginning of the project. These lines are more productive of seed and perhaps less inclined to shed their seed at maturity. There is also firm evidence that the selected lines vary in the composition of their oil, the white-flowered Spanish genotypes having a lower contaent of GLA and erucic acid than others. There are indications that some of the selected lines have a GLA content about 2 per cent higher than the English land race, though further analyses are needed to confirm this. However, due to the adverse correlations between oil content and composition, it is to be expected that these lines will have a high erucic acid content and a low overall content of oil. Thus the genetic basis now exists on which to produce borage crops with reliably high seed yield, high GLA content or low erucic acid content, though not with all three of these desirable characteristics.

Acknowledgements We are grateful to BioCrops Ltd for funding this project, to Dr B. F. Bland for providing seed stocks and assisting with the management of trials, to a number of collaborators in Spain, especially Ing. M. Carravedo, and to the curators of many botanic gardens, for providing seed stocks, and to Professor F. Gunstone for conducting the oil analyses.

\section{REFERENCES}

CROWE, L. K. 1971. The polygenic control of outbreeding in Borago officinalis. Heredity, 27, 111-118.

HORROBIN, D. F. 1983. The regulation of prostaglandin biosynthesis by the manipulation of essential fatty acid metabolism. Rev. Pure appl. pharmacol. Sci., 4, 339-383.

HORROBIN, D. F. 1984. Placebo-controlled trials of evening primrose oil. Swedish J. biol. Med., 3, 13-17.

HORROBIN, D. F. AND MANKU, M. S. 1983. Essential fatty acids in clinical medicine. Nutrition and Health, 2, 127-134.

LARSON, K. M., ROBY, M. R. AND STERMITZ, F. R. 1984. Unsaturated pyrrolizidines from borage, Borago officinalis, a common garden herb. J. Nat. Prod. (Lloydia), 47, 747-748.

RESCHKE, A. 1983. Capillary gas chromatographic determination of rosmarinic acid in leafy species. Z. Lebensm. Unters. Forsch., 176, 116-119.

THEIMER, R. R. AND SCHUSTER, R. 1978. Light dependent inhibition of germination and early seedling development of Borago officinalis. Z. Pflanzen physiol., 90, 111-118.

VAN VALEN, F. 1979. Contribution to the knowledge of cyanogenesis in angiosperms, part 12. Cyanogenesis in Boraginaceae. Proc. K. Ned. Aked. Wet., Ser. C., Biol. Med. Sci., 82, 171-176. 